\title{
Pesquisa de campo em comunidades on-line sobre corridas ilegais de rua: velocidade, risco e masculinidade
}

\author{
LeILA Sollberger Jeolás
}

resumo $\mathrm{O}$ artigo é parte de um projeto de pesquisa e objetiva compreender a conduta de risco presente nas corridas ilegais de rua, ou "rachas" de carro, e os significados que elas têm para os jovens que as praticam. A velocidade adquiriu valor central nas sociedades ocidentais modernas, nas quais proliferaram várias formas de risco, produzindo, ao mesmo tempo, incertezas e busca de segurança. Contrariamente à forma como os riscos são controlados em um mundo tecnologizado e securitário, alguns grupos juvenis buscam a eles se expor, amplificando-os e desafiando-os, às vezes, até o limite da vida e da morte. A velocidade aparece como um dos principais traços da revoluçáo urbana e da vida moderna e o automóvel uma das sínteses possíveis das mudanças ocorridas. O objetivo desse artigo é apresentar consideraçóes teóricas iniciais sobre o tema, a partir da análise de listas de discussão na Internet, e observaçóes metodológicas sobre o estudo de uma prática ilegal que instiga a abordagem etnográfica.

palavras-chave Juventude. Velocidade. "Rachas”. Automóveis. Risco.

\section{Introdução}

O presente artigo é parte de um projeto de pesquisa cujo objetivo é compreender a conduta de risco presente nas corridas ilegais de rua, ou "rachas" de carro, e os significados que elas têm para os jovens que as praticam. Trata-se de compreender os significados atribuídos pelos jovens à experiência da velocidade e do risco presente nessas práticas, uma vez que a velo- cidade adquiriu valor central nas sociedades ocidentais modernas, nas quais proliferaram várias formas de riscos, dos mais aceitáveis, que contam com a anuência social, aos mais temidos, de caráter global e que causam, ao mesmo tempo, grande incerteza e busca de segurança. Contrariamente à forma como os riscos são negados e controlados em um mundo tecnologizado e securitário, alguns grupos juvenis buscam deliberadamente a eles se expor, não para reduzi-los, mas para amplificá-los, incitar desafios e afrontar perigos, indo, às vezes, até o limite da vida e da morte. Vários são os autores que tomam a velocidade como um dos traços mais importantes da revolução urbana e da vida moderna (Sennet, 1997; Virilio, 1999), sendo o automóvel uma das sínteses possíveis das mudanças ocorridas. O fascínio pela potência dos motores e pela velocidade, alimentado pelas indústrias, transformou a velocidade em uma nova forma de êxtase possibilitada pela revolução técnica (Kundera, 1995).

O objetivo deste artigo é apresentar algumas consideraçóes teóricas iniciais sobre um tema de pesquisa pouco estudado nas Ciências Sociais (Featherstone, 2004), a partir da análise de conteúdo de listas de discussão na Internet, e algumas observaçóes metodológicas sobre o estudo de uma prática ilegal que ocorre sem lugar nem hora marcada, apresentando um desafio à abordagem etnográfica ${ }^{1}$.

Por se tratar, justamente, de uma prática ilegal, meu primeiro contato com o tema foi feito 
por meio de pesquisa realizada em listas de discussão de comunidades on-line sobre velocidade. Além do material coletado nessas listas, dei início, ao mesmo tempo, à pesquisa de campo com a ajuda de um estudante que pratica "rachas" há vários anos e, mais recentemente, participa de "rachas" organizados quinzenalmente no autódromo da cidade de Londrina, representando, portanto, uma tentativa de institucionalização dessa prática. O objetivo é associar a pesquisa realizada na Internet à pesquisa de campo, de modo a apreender os significados elaborados pelos jovens sobre a experiência da velocidade, inseridos no fluxo de suas práticas.

Nos limites deste artigo abordarei apenas essa etapa inicial da pesquisa na Internet e farei algumas considerações sobre a utilização do ciberespaço na prática e na abordagem etnográficas, principalmente acerca de como se processa a técnica de pesquisa constitutiva do método etnográfico, a observação participante, quando o campo é a Internet. A principal dificuldade por mim encontrada, em razão das especificidades do campo e do tema estudado, foi para passar da observação - o pesquisador como leitor das listas de discussão e os textos como material para análise de conteúdo - à participação - o pesquisador interagindo com os participantes do grupo. A investigação em andamento exemplifica como a articulação da pesquisa de campo àquela realizada na Internet mostra-se uma estratégia positiva para o enfrentamento das dificuldades apresentadas quando o campo diz respeito a uma prática ilegal e que ocorre sem previsão de tempo e de espaço, no calor da hora, ou então comunicada entre os seus praticantes mais próximos.

\section{Procedimentos metodológicos: a Internet como campo de pesquisa}

Há muito tempo que o método etnográfico teve que ser repensado criticamente diante de "novos" campos e objetos de pesquisa. Aplicado inicialmente para estudar sociedades tradicionais, indígenas ou "tribais", as quais se pretendia apreender em sua totalidade, o método etnográfico, ao se voltar, posteriormente, para o estudo das sociedades moderno-contemporâneas, teve que ser readequado em suas técnicas e abordagens, adaptando-se a objetos de estudo e campos de pesquisa náo mais focados em um grupo circunscrito no espaço e no tempo. Marcus (1995) fala de etnografias multissituadas para a análise de sociedades transnacionais ou translocais. Outro exemplo são as pesquisas etnológicas realizadas entre populações indígenas brasileiras que apresentam ritmos descontínuos, visitas mais ou menos curtas ao longo de um amplo período de campo, denominadas por Ramos (1990) "etnografias em movimento”. Atualmente, o debate sobre o papel da etnografia ganha ênfase na antropologia contemporânea, quando a importância do local e da experiência vivida em um mundo globalizado é reforçada e analisada criticamente (Marcus, 1991; Peirano, 1995; Hannerz, 2003).

Nesse sentido, a etnografia como marca fundamental do trabalho antropológico vem adquirindo novas dimensóes quando o campo é a Internet, o que leva à necessidade de atualizar e aprofundar a discussão sobre as características das etapas desse processo. As pesquisas realizadas com usuários da Internet ou com comunidades virtuais, conforme Guimarães Jr. (2000) e Rifiotis (2002), mostram os limites e as possibilidades de se realizar um trabalho de campo no ciberespaço, bem como permitem discutir criticamente algumas das especificidades do trabalho antropológico: como realizar a observação direta, participante e de longa duração; como coletar dados e redigir o caderno de campo; e como realizar entrevistas que não se dão face a face.

Iniciei minha pesquisa sobre "rachas" de carros em listas de discussão de comunidades 
do Orkut, selecionadas aleatoriamente, para poder aproximar-me do tema e de um universo tão distante de mim - os significados atribuídos pelos jovens à experiência da velocidade e do risco aí implicado. O meu objetivo era tornar esse universo exótico mais familiar (Velho, 1981), ou seja, tentar diminuir a estranheza inicial, desfazendo valoraçóes e estereótipos, para compreender tais práticas e os significados a elas atribuídos de dentro e de perto e náo de longe e de fora (Magnani, 2002). Para tanto, busquei aprender a linguagem própria desses grupos juvenis, os termos técnicos e as gírias do universo masculino dos motores, da aceleração e da potência, ao qual, até então, não tinha acesso.

O Orkut, novo recurso das redes eletrônicas de comunicação e de sociabilidade ${ }^{2}$, tem grande potencialidade como fonte de pesquisa, pois traz uma gama variada de assuntos e de áreas de interesse articuladas em comunidades criadas por qualquer pessoa para se conectar com outras que compartilham o mesmo interesse por um determinado tema.

No caso de minha pesquisa, devo ressaltar que nessa primeira etapa realizada no ciberespaço encontrei-me na situação de espreitadora (lurker), termo "nativo" utilizado para definir alguém que se posiciona apenas como leitor das listas de discussão da Internet e não troca ideias nem interage com os participantes das listas. Sei que a "participação" antropológica não deve se restringir à "observação", mas encontrei-me como um(a) iniciante, apreendendo duas linguagens, a do ciberespaço e a dos motores e da velocidade. No primeiro caso, tratava-se da linguagem de socialização no ciberespaço: desde a relação com a interface e o domínio dos comandos até a apreensão da netiqueta e dos signos, como os emoticons, que permitem uma oralidade escrita, dinamizando e dando um "tom” à conversa, através da expressáo de sentimentos e de estados de espírito. No segundo caso, estava em questão o aprendizado da linguagem técnica relacionada a carros, motores e velocidade, linguagem tradicionalmente de domínio masculino na sociedade brasileira e, de modo geral, ausente do processo de socialização das mulheres. Sem essa dupla iniciação não poderia sequer apresentarme como pesquisadora, pois o conhecimento mínimo da linguagem e do universo investigado é pressuposto para poder elaborar questóes e estabelecer comunicação.

Apesar de ter sido aceita em todas essas listas pesquisadas, decidi, neste primeiro momento, não participar ativamente de nenhuma das discussóes, pois em uma tentativa realizada pude perceber como a identificação de pesquisadora, mais velha do que eles e mulher, introduzia um tom pouco espontâneo às discussôes, que acabavam por não se desenvolver por muito tempo. As respostas às minhas questóes pareciam dirigidas a essa personagem, a pesquisadora, e tornavam-se mais formais, perdendo o tom apaixonado que eu podia verificar quando situada apenas como observadora.

O que leva à afirmação de que a necessidade de desenvolver uma observação participante no ciberespaço deve ser avaliada em cada caso específico de pesquisa e não tomada como um pressuposto geral. Em alguns casos, a pesquisa na Internet tem apontado uma maior facilidade para tratar de assuntos de difícil abordagem, caso da anorexia (Silva, 2004) e de procedimentos cirúrgicos para extração da gordura corporal (Latanza, 2007). No primeiro caso, a pesquisadora demonstra a importância da pesquisa no ciberespaço, pois a maioria dos grupos que se articula em torno do tema da anorexia não se encontra no face a face, pretendendo resguardar o anonimato, o que possibilitou, segundo ela, que sua observação participante realizada somente na Internet se aproximasse da experiência de sociabilidade específica do grupo estudado (Silva, 2004, p.32). Além disso, a relação pesquisador-pesquisado na observação 
participante foi facilitada pela exposição de sua própria trajetória pessoal de regimes, dietas e problemas com o peso, pelo fato de ser mulher, jovem e familiarizada com o universo cultural das participantes, fazendo com que ela fosse considerada mais um membro do grupo do que uma intrusa em busca de dados para pesquisa ou para reportagens ${ }^{3}$. No caso do trabalho de Latanza (2007), embora a relação tenha sido menos longa e intensa do que a relatada por Silva (2004), há o mesmo tipo de interesse genuíno pelo assunto por parte da pesquisadora, fato percebido pelos participantes, que a aceitaram como alguém que compartilhava com elas o possível interesse de realizar uma lipoaspiração ou uma cirurgia plástica.

No caso de minha pesquisa, ocorreu justamente o inverso, ou seja, uma não identificação da pesquisadora com o assunto e com o universo dos motores e da velocidade, que se traduzia tanto nos marcadores de diferenças de geração, gênero e classe social, como no ainda precário conhecimento dessa linguagem e desse universo, distanciando-me, portanto, dos jovens pesquisados ${ }^{4}$. Entretanto, mesmo posicionando-me apenas como "observadora" das listas de discussão, o caderno de campo se fez imprescindível desde o início, pois foi possível anotar informações sobre seus participantes - se são conhecidos ou desconhecidos; se estabelecem interaçóes ou redes de amizade; se há referências a locais, eventos ou pessoas em comum. Mais do que isso, foi um instrumento que permitiu formular questóes sobre o que se observava, além de permitir buscar recorrências significativas daí depreendidas. Outra fonte importante para obtenção de informações foram as fotos, postadas pelos participantes dessas listas, de si próprios e/ou de seus carros. Elas permitiram, igualmente, uma importante análise dos valores compartilhados nesse universo. Mas, apesar do desenvolvimento dos recursos audiovisuais na Internet, é bem verdade, como afirma Rifiotis (2002), que a maior parte das interaçóes se estabelece com base textual. Nas palavras do autor, o que implica "um trabalho de campo de estilo muito particular, pois o que há para 'ver' em campo na maior parte do tempo são textos" (2002, p.12).

Além da dificuldade apresentada para passar da observação à participação na pesquisa realizada na Internet, outra questão presente nos debates sobre a metodologia de pesquisa no ciberespaço refere-se à relação entre pesquisa on-line e off-line. Vários autores defendem que não se deve definir a priori a necessidade de associar as duas, partindo do pressuposto de que o virtual se opóe ao real, definindo-se, portanto, como irreal ou imaginário (Guimarães Jr., 2000; Lévy, 1996; Miller; Slater, 2004; Rifiotis, 2002). Essa distinção simplista é criticada por esses autores, que apontam uma relação complexa e de complementaridade entre ambos, na qual o virtual constitui uma esfera do real e o transforma na medida em que subverte seus limites de espaço e de tempo. Há casos em que a pesquisa on-line mostra-se mais apropriada, a exemplo do trabalho de Slater (apud Miller; Slater, 2004) sobre a troca de sexpics no Internet Relay Chat (IRC), quando o tema da pesquisa impossibilita o acesso off-line. Cito também, como exemplo, a pesquisa de Guimarães Jr. (2000), que buscou compreender as especificidades das interaçóes estabelecidas em uma plataforma de sociabilidade multimídia, o $\mathrm{Pa}$ lace, cujos membros participantes são oriundos de diversos estados brasileiros e náo realizam encontros off-line, sendo esses últimos mais comuns nos ambientes baseados em plataformas como a IRC. Mas, por outro lado, há casos em que o estudo mostra que a sociabilidade se dá em torno dos dois tipos de contato, o on-line e o off-line, como demonstra Dornelles (2004) em sua pesquisa sobre salas de bate-papo virtual (chats) na cidade de Porto Alegre, Rio Grande do Sul. Nas palavras de Guimarães (2000, 
p. 145), a opção entre etnografia on-line ou off-line, ou ainda de articulação das duas "não pode ser tomada a priori, mas deve considerar critérios como a natureza do problema sob investigação, a disponibilidade dos informantes e mesmo as contingências físicas”.

No caso da pesquisa aqui apresentada, considero fundamental a articulação da pesquisa na Internet àquela realizada no campo, pois uma alimenta a outra, além de ter se constituído em importante estratégia para enfrentar as dificuldades de realizar uma etnografia sobre uma prática ilegal como a dos "rachas" que, além disso, ocorre em diferentes pontos da cidade, em horários diversos, de forma casual e imprevisível. Atualmente, com a pesquisa de campo em andamento e vários contatos com atores desse universo dos "rachas" na cidade de Londrina, continuo a observar, juntamente com meu aluno praticante de "rachas", outras listas de discussão na Internet, focando, agora, aquelas cujos participantes são moradores da cidade e participam de redes de sociabilidade e de locais de encontro relacionados a este universo. A articulação da pesquisa on-line e off-line tem possibilitado uma maior aproximação com esse universo, trazendo contornos mais precisos a uma prática tão fluida e, ao mesmo tempo, permeada de regras, linguagem e códigos precisos e que apresenta uma heterogeneidade interna bastante acentuada, dependendo do tipo/marca do carro ou moto, perfil sociocultural dos praticantes, estilos baseados em gostos e preferências e locais frequentados 5 . Tanto a pesquisa de campo iniciada quanto as comunidades on-line pesquisadas deixam entrever redes de sociabilidade, gostos e preferências específicos que contribuem para a construção de processos identitários mais ou menos demarcados, mais ou menos intensos, sendo necessário delinear os contornos dessas redes de sociabilidade.

De acordo com Guimarães Jr. (2000), ao discutir as relações dinâmicas e fluidas que se estabelecem no ciberespaço, pode-se falar em dois tipos de comunidades: as "fortes", caracterizadas por relaçóes mais intensas, pelo engajamento em atividades de grupo, pelo sentimento de pertencimento e códigos e estilos comuns compartilhados; e as "fracas", constituídas por participações esporádicas e descompromissadas. No campo percebem-se, igualmente, grupos que se formam no contexto de redes mais extensas e fluidas, cujos limites se constroem em torno de oficinas mecânicas especializadas em turbinar ou tunar ${ }^{6}$ carros $\mathrm{e}$ motos, de mercados de peças, legais e ilegais, de postos de gasolina - locais de encontro e de lazer -, de encontros regulares promovidos pelos clubes locais dos dodgeros e opaleros, dentre outros, e de eventos realizados no autódromo da cidade.

Por ora, a análise apresentada nos limites deste artigo restringe-se às listas de discussão de comunidades on-line sobre a experiência de jovens com a velocidade, cujos significados busquei interpretar através das técnicas da análise de conteúdo. Das mais de 500 comunidades localizadas por ocasião da primeira busca realizada, selecionei, aleatoriamente, três delas para o estudo, das quais analisei, durante seis meses, os seguintes tópicos de discussão sobre a velocidade atingida, os tipos de carro utilizados, risco e morte: "Qual o seu carro e a máxima”, "Qual a velocidade mais alta que já pegou?", "Qual seu record? Quantos KM/Hr", "Roleta Russa”, "Mais um que morre da comunidade que se achava o Senna", "Rachas e Pegas"

Do material analisado, pude depreender dois núcleos de significados a serem apresentados para a discussão: a busca da vertigem e o reforço de um estilo de masculinidade. De um lado, a busca de sensaçôes corpóreas que possibilitam a alteração do estado de consciência dos registros da percepção do tempo (realidade suspensa), do peso e da gravidade do corpo, permitindo a produção de vertigem e 
intensificação dos sentidos amortecidos pela modernidade, que habituou os corpos à rapidez e à aceleração (Sennet, 1997). De outro, a presença de valores associados à competitividade, à potência e desempenho do motor, ao conhecimento e domínio da técnica para alcançar velocidades altas, atuando como símbolos de prestígio na construção de um estilo de masculinidade.

\section{Velocidade e risco nas interfaces de gênero e de geraçáo}

A pesquisa se situa entre os estudos que tomam o risco como foco central da análise e demonstram o seu potencial para a compreensão das sociedades ocidentais modernas. O desenvolvimento acelerado da ciência e da tecnologia produziu incertezas e riscos e, grande parte deles, de caráter global. Por essa razão, os estudos sobre risco ganharam visibilidade nas Ciências Sociais em função da importância e da polissemia que o risco adquiriu nas sociedades ocidentais modernas. Entre os autores que tomam o risco como foco de análise, os sociólogos Giddens, Beck e Lasch (1997) consideram, principalmente, os riscos ambientais e tecnológicos e suas graves consequências como ponto de partida para a compreensão do projeto histórico da modernidade. Beck (2008, p.2) afirma que a "sociedade moderna se tornou uma sociedade de risco à medida que se ocupa, cada vez mais, em debater, prevenir e administrar os riscos que ela mesma produziu”. Trata-se, portanto, de estudar a insegurança e os riscos produzidos pelo próprio processo de modernização, como efeitos secundários e contínuos do desenvolvimento tecnológico (Kanashiro, 2008; Rodrigo, 2008). São riscos globais e coletivos que demandam uma nova abordagem na sua comunicação e no seu enfrentamento (Di Giulio; Figueiredo; Ferreira, 2008; Rodrigo, 2008).
Outros autores focalizam mais especificamente o plano das percepçóes de risco em diferentes contextos sociais e culturais (Douglas, 1994, 1996; Peretti-Watel, 2003). No campo da antropologia, Mary Douglas (1976, 1994, 1996) realizou vários estudos sobre percepção de risco, com o objetivo de elaborar uma teoria cultural dos riscos a partir da análise de como diferentes tipos de organização social elaboram diferentes percepçóes de risco e reações diversas para dar significados a eles e enfrentá-los. A sua análise enfatiza como os valores e os princípios morais afetam a percepção de risco, existindo uma relação entre poluição moral e ordem social nas sociedades tradicionais e nas modernas. Para ela, portanto, o risco não se reduz à probabilidade de um evento negativo acontecer, mas diz respeito, muito mais, à magnitude provável dos resultados do evento e ao valor social atribuído a esse resultado num determinado contexto cultural.

Nesta perspectiva, os estudos de Le Breton (1991, 2004) sobre os sentidos que o risco adquiriu nas sociedades ocidentais contemporâneas são referência, pois enfatizam o gosto pelo risco (dos empreendedores, dos desportistas, dos guerreiros) por parte daqueles que buscam e valorizam a experiência do risco. Ele estuda domínios da existência - de lazer ou ligados a profissóes - em que o risco pode ser valorizado, expondo os sujeitos a seus efeitos. $\mathrm{O}$ autor propóe analisar as condutas de risco como um jogo inconsciente com a morte, em que o sujeito busca elaborar, como um bricoleur, sentido e valor para sua existência, uma vez que as sociedades modernas sofrem de um eclipse do simbolismo coletivo e levam o sujeito, cada vez mais, a contar consigo próprio nessa busca de sentido. Seus trabalhos servem de referência para a pesquisa em desenvolvimento sobre os "rachas", uma vez que possibilitam aprofundar a compreensão da exposiçáo de grupos juvenis ao risco da velocidade e à possibilidade - maior ou 
menor - de perder a vida, no contexto de uma sociedade obcecada por segurança, preservaçáo e prolongamento da vida (Ribeiro, 2003). Entretanto, se as figuras de risco propostas por Le Breton (1991) - vertigem, afrontamento, apagamento, sobrevida - apresentam-se como importante síntese teórica, que pode servir de guia para a compreensáo dos sentidos que adquirem as práticas de risco atualmente, elas devem ser tomadas mais como um ponto de partida para a análise do que como um modelo classificatório estanque, que não daria conta da dinâmica das condutas de risco nas trajetórias de vida dos jovens pesquisados.

A variação dos grupos existentes no universo dos "rachas", apresentando estilos, gostos, linguagens e símbolos de identificação diversos, impóe a necessidade de um trabalho etnográfico que possa dar sentido às condutas de risco contextualizadas nas práticas de grupos específicos, ao mesmo tempo em que contribui com os contornos necessários para a compreensão das culturas juvenis contemporâneas.

No contexto etnográfico específico dos jovens que praticam "rachas", o risco relacionado à velocidade é dinamizado e concretizado e adquire diferentes sentidos no desenrolar de suas vidas. Para alguns jovens, a velocidade é experimentada como um engajamento lúdico; para outros, como um desafio e uma prova na qual eles testam suas próprias possibilidades pessoais e afrontam os outros; uns se confrontam com o risco progressivamente, outros o fazem em um impulso vigoroso de excitação; para uns, o controle, o racional e as precauçóes tomadas prevalecem, para outros, a perda de controle, o irracional e a exposição ao risco sem precauçôes; para uns, a expressão de um gosto, para outros, a manifestação de um desgosto em relação à vida.

Para poder dar conta dessas nuanças, a abordagem teórica precisa apreender os significados das açóes dos sujeitos, sempre orientadas por lógicas institucionais do passado e submetidas às pressōes dos dispositivos sociais, mas, ao mesmo tempo, permanentemente ressignificadas nas práticas sociais. As trajetórias dos jovens pesquisados e suas histórias de vida, a serem coletadas durante a pesquisa de campo em andamento, deveráo, pois, ser analisadas a partir de abordagens da teoria da prática que buscam compreender o entrelaçamento das coerçôes socioculturais e das açôes dos sujeitos, ou melhor, a interdependência entre as forças de transformação mais amplas da vida social e as dimensóes das interaçóes dos atores sociais. O desafio é grande e refere-se, segundo Ortner $(2007$, p.50), à construçáo de uma teoria da prática na qual "nem os 'indivíduos' nem as 'forças sociais' têm 'precedência', mas na qual há, contudo, uma relação dinâmica, forte e, às vezes, transformadora entre as práticas de pessoas reais e as estruturas da sociedade, da cultura e da história".

No caso de uma análise sobre os "rachas", são fundamentais os estudos atuais sobre corpo (Almeida, 1996; Featherstone; Hepworth; Turner, 1992; Le Breton, 1990, 2003, 2006a), sobre os processos de incorporaçáa ${ }^{8}$ (Bourdieu, 1994, 1996; Csordas, 2008), sobre o papel dos sentidos (Le Breton, 2006b; Virilio, 1999), das emoçōes (Lacroix, 2006) e de uma nova sensibilidade (Sennet, 1997; Spink, 2003) adquirida com relaçáo à velocidade e à aceleração. Essas abordagens mostram a emergência de práticas que valorizam as sensaçóes corpóreas produtoras de vertigem, renúncia da consciência e embriaguez dos sentidos (Le Breton, 1991), que se contrapóem às formas de controle social, de autodomínio e de disciplina próprias das sociedades modernas (Foucault, 1985, 1979; Elias, 1994, 2006).

Os jovens que praticam "rachas" aprenderam a linguagem dos motores e da velocidade em seu processo de socialização, comumente dos pais, tios, vizinhos ou amigos, e exercita- 
da ao longo de sua história pessoal. Essa linguagem prevalece no mundo masculino, daí a importância da categoria de gênero para a análise. A predominância de homens jovens nos "rachas", corridas, acidentes de trânsito e outras práticas relacionadas à velocidade (mas não só) remete à análise da construção de estilos de masculinidade (Cechetto, 2004) como processos históricos, nos quais diferentes grupos sociais elaboram significaçóes que interrelacionam risco e masculinidade (Sánchez, 2005). O afrontamento físico, a formação para o combate, o estímulo para a competição e o domínio da tecnologia são alguns dos elementos presentes na socialização dos homens jovens e nas representaçóes de masculinidade, havendo uma pregnância dos valores associados à violência e ao risco na construção social do gênero masculino, longamente enraizados na cultura ocidental moderna (Machado, 2004), embora, nas práticas sociais, tais valores sejam elaborados de diversas maneiras e com ênfases diferentes.

No caso da pesquisa sobre os "rachas", a masculinidade parece se manifestar na potência e na integração que os jovens estabelecem com a transformação/criação desses veículos, seja aumentando a potência do motor (do seu "ronco"), dos amplificadores de som, ou criando uma estética muito particular dos carros e das motos. A singularização dessa integração se constitui através da identidade entre criador e veículo (máquina) transformado. O domínio e a transformação da máquina parecem ser centrais para garantir aos seus proprietários ou condutores um lugar de destaque e de prestigio nas condutas de risco no universo dos motores e da velocidade. A relação existente entre, de um lado, a tecnologia dos motores e da velocidade e, de outro, a construção de estilos de masculinidades e práticas de risco, se faz pelo reforço de habilidades masculinas para atividades que envolvem força física, desempenho, domínio técnico, competição, coragem, audácia, dentre outras (Bourdieu, 1995; Almeida, 2000), presentes na socialização dos homens e na representação da masculinidade hegemônica em nossa cultura (Connell, 1997; Kimmel, 1998) ${ }^{9}$.

Além do gênero, outra categoria que se mostrou importante para a análise foi a de geração. De modo geral, as condutas de risco impóem a sensação de reconhecimento, tão valorizada na sociedade contemporânea e, no caso dos jovens, associada à rebeldia e à transgressão (Pais, 2004). Nos "rachas", o fato de ser uma prática ilegal traz ainda a associação da tensão e do medo de ser apanhado pela polícia, permitindo aos jovens que a praticam a expressão do sentido de individualidade e a possibilidade de ganhar um nome próprio entre seus pares - a figura do herói atualizada, diríamos. Fornece uma linguagem de pertencimento reforçado pelas diferenças de gênero e de geração, fontes de autodefinição identitária.

O processo de globalização da cultura se instaura a partir dos anos 1950, com a expansão da cultura de massas e das mídias eletrônicas, juntamente com outras mudanças econômicas e políticas que se verificam, intensificando o processo de criação de culturas juvenis (Feixa, 1998; Morin, 1986). No Brasil, os jovens passam a adquirir maior visibilidade nos centros urbanos, "entram em cena” (Abramo, 1994), são alvo da indústria cultural, produzindo novas demandas de comportamento e de consumo (Madeira, 1986) com a criação de estilos de vida diversos.

A associação velocidade e juventude, divulgada pelo cinema, a partir dos anos 1950 , apoiou-se em modelos paradigmáticos de rebeldia e de inconformismo juvenil associados aos carros, às motocicletas, às jaquetas de couro e ao rock. James Dean foi uma dessas figuras que passou a enfatizar uma nova maneira de encarar a vida: viver intensamente e, consequentemente, arriscar-se. No Brasil, de acordo 
com Carmo (2001), na década de 1960, com a primeira geração do rock brasileiro, já se ouvem notícias dos "rachas" de automóveis nas capitais do país. Nos anos de 1970 e 1980, eles eram praticados principalmente por jovens das classes médias urbanas, tendo ocorrido, de lá para cá, a extensão dessas práticas para jovens com menor poder aquisitivo.

Atualmente, pelo que pude observar na pesquisa de campo, há uma presença significativa de jovens com menor poder aquisitivo e, no caso dos "rachas" de motos de baixa cilindrada, há prevalência de jovens da periferia. Os "rachas" parecem possibilitar aos jovens das classes populares urbanas (motos de baixa cilindrada) e àqueles de segmentos da classe média (carros "tunados") produzir os seus próprios carros, ou seja, criá-los à sua própria imagem, dando-lhes uma fisionomia própria. Os carros e as motos constituem verdadeiras extensóes dos corpos desses jovens, remetendo-nos à relação histórica do homem com a máquina (Parente, 1993; Haraway, 2000). São corpos-máquinas, no sentido de que formam uma única peça, funcionam e se movem sincronicamente, em uma mesma sintonia ou mesma frequência. Etimologicamente, sintonía remete a "forte tensão do corpo, dos órgãos, tensão do espírito" (Houaiss, versão eletrônica), permitindo explicar a intensidade das sensaçóes explicitadas pelos jovens ao sentirem, em seus próprios corpos, as vibraçóes, os sons e os cheiros do carro ou da moto. Através dessa relação, os jovens exibem potência (dos motores) e ganham prestígio entre os pares, seja pela "criação" ou transformação das máquinas que ganham personalidade, seja pelo domínio sobre elas, no sentido de as conduzirem com conhecimento e destreza técnica. Eles se apresentam publicamente, se expóem através de seus carros, como se os dois apresentassem analogias nas características, em que a potência do motor atua como um tipo de metáfora da potência de seu dono ou condutor.
O que se poderá observar na análise das falas dos jovens, retiradas das listas de discussão de comunidades do Orkut e aqui apresentadas, é uma ambivalência entre controle e descontrole, risco e segurança; a mesma ambivalência presente nas sociedades atuais entre liberação da paixão e gestão do risco; entre busca de liberdade, ligada à transgressão das normas sociais, e busca de segurança e proteção na reprodução da vida social.

\section{A busca da vertigem: entre a "loucura" e o "controle"}

A hipótese teórica a ser discutida é a de que a experiência da velocidade pode representar, para os jovens, uma reaçáo ao mundo atual, dominado pela tendência à massificação e às formas de controle social e de autodomínio (Foucault, 1979, 1985; Elias, 1994). O pressuposto é o de que a modernidade produz uma intensificação dos sentidos, mas, ao mesmo tempo, amortece-os (Sennet, 1997; Virilio, 1999), pois expóe os corpos à rapidez dos acontecimentos e das referências que se multiplicam ao sabor da moda e do consumo (Balandier, 1988, 1994; Augé, 1994).

Ao analisar os significados enunciados pelos jovens quando se referem às sensaçóes e emoçóes produzidas na experiência com a velocidade, observa-se uma tensão entre o desejo do "descontrole" e a necessidade do "controle". Apesar de grande parte deles se referir à busca da "loucura" nas sensaçóes produzidas pela velocidade, muitos expressam uma tensão constante entre, por um lado, essa "loucura" ou busca da vertigem e a sensação de sair de si e, por outro lado, a necessidade do controle, do domínio, do desempenho, do conhecimento do carro, do motor e do ato de conduzir (destreza). Por isso, o termo "loucura" vem associado não apenas ao descontrole e à vertigem, 
mas também à ideia de "vacilo", de "marcar" (no sentido de "bobear"), ou seja, de "perda do controle", de "desatenção", de "falha" e de "exagero". Percebe-se que, embora os jovens busquem a "loucura" produzida pelas sensaçôes experimentadas com a velocidade, sinônimo de descontrole de si, eles sabem que o descontrole total está associado à possibilidade de risco e, portanto, de morte.

A recorrência do termo "loucura" nas falas dos jovens refere-se às sensaçôes vivenciadas: "loucura pura!"; "180 km/h e naum tive coragem d andar mais, o cara começa a tremer todo mas a sensação é boa pra caralho"; "foi uma loucura, parecia que o carro ia voar ou então explodir!"; "sensação muito loca, vc sente tudo leve e muito loco, sensação ótima [...] melhor sensação que existe!!”.

Muitas das sensaçóes descritas falam do ruído do motor e do tremor experimentado pelo corpo. Um jovem entrevistado chegou a me dizer que fica "possuído", "tomado", como se o seu corpo "se despregasse" e náo fizesse mais parte dele. $\mathrm{O}$ som do motor e a sua trepidação se misturam às sensaçóes corporais e, no caso de muitos carros, associam-se ainda ao som potente da música, na maior parte das vezes derivadas do rock. Eles se referem, igualmente, com constância, às sensaçóes corporais (os pelos do corpo arrepiados) com relação ao cheiro da gasolina e ao da borracha queimada dos pneus nos burnouts ou borraçóes ${ }^{10}$.

Le Breton (1991) fala de "renúncia da consciência", de "embriaguez dos sentidos". A velocidade, o som (o ronco) e a vibração do motor são estimulantes da excitação e levam à alteração do estado de consciência, produzindo vertigem (Caillois, 1986). Se esta superexcitação dos sentidos e, ao mesmo tempo, perda de si levam a pensar em uma certa autonomia do carro, presente em suas falas, dada a potência do motor que parece adquirir vida própria, os jovens expressam, igualmente, a ideia de um domínio do homem sobre a máquina quando afirmam que "quase akabei com o motor dele!”; "Quase acabei com o carro". Chamam a atenção para uma cumplicidade que une o desenvolvimento técnico e científico e o fascínio crescente pela velocidade em nossos dias (Virilio, 1996, 1999).

O domínio sobre a máquina, diretamente ligado à construção da masculinidade, aparece com duplo sentido: o primeiro refere-se ao conhecimento e domínio técnico do motor, "preparado" e "turbinado"; o segundo refere-se ao domínio na condução do carro em alta velocidade, apesar da busca da sensação de vertigem. Novamente, uma tênue linha entre o controle e o descontrole. Oscila-se entre o domínio (do conhecimento do motor, da técnica de condução, da atenção redobrada) e a sensação de extremo prazer, de deixar-se levar pelo carro. Conjugase o sentimento de vertigem com o do controle físico da situação.

O contraponto da busca da vertigem é a relação concreta com a morte. Presente nos tópicos de discussão "Roleta Russa” e "Mais um que morre da comunidade que se achava o Senna", a morte aparece, nas falas dos jovens, em toda a sua ambivalência e ambiguidade. A maioria considera uma prática perigosa e afirma ser preciso "manerar", ter cautela, controle da técnica e não "dar vacilo". A fala de um jovem é significativa:

Infelizmente somos apaixonados por uma brincadeira ou esporte (náo sei como chamar) muito perigosa e violenta [...] brincadeira essa que naum admite erros nem falhas [...] em um estande, adrenalina a mil, empolgação, sorrisos e euforia, sensaçóes essas quem naum tem como se explicar [...] mas em um momento um vacilo um único vacilo é o suficiente [...] tudo se acaba [...] como se por um momento o mundo parasse e a única coisa a sentir é um aperto forte no coração e um pensamento de naum acredito. Só ai 
paramos para pensar como nossa vida e frágil e a merda que uma pisada mais forte no acelerador pode fazer [...].

Jogo inconsciente com a morte para saber se viver tem sentido. Troca simbólica, segundo Le Breton (1991), na qual o corpo se torna moeda e se exalta a vida com uma dimensão heroica e um sentido de identidade pessoal. Mas jogo sério, como se as descontinuidades de sentido experimentadas permanentemente em nossas sociedades se resolvessem na busca última do limite físico, possibilitando ao indivíduo assegurar-se de sua existência, desafiando os limites da própria coragem.

De acordo com os jovens, a velocidade é uma prática que não admite erro e o domínio técnico é uma exigência: "Cometeu um erro e pagou caro"; "Às vezes é preciso manerar"; "ter consciência"; "não admite falhas [...]". Por isso, alguns questionam a prática de "tirar racha", pois o sentido de competição aí inerente pode levar à "perda do controle". Um rapaz afirma: "[...] mesmo o racha sendo ilegal eh preciso responsabilidade [...] vc precisa saber os seus limites e ter em sua cabeça q vc não eh o super homem". Também a roleta russa é criticada por alguns, pois, segundo eles, se coloca em risco não apenas a própria vida, mas também a dos outros. Eles afirmam que pagar com a própria vida "por esses segundos de adrenalina" ainda se pode aceitar, mas a "irresponsabilidade com a vida dos outros" não é aceitável e um jovem afirma: "se quer se matar faça sozinho sem prejudicar os outros [...]".

Essa discussão remete a outra, sobre a institucionalização dos "rachas", iniciativa que ocorre em Londrina, organizada por um amante das práticas relacionadas aos "rachas", arrendando quinzenalmente o autódromo da cidade, mais especificamente uma reta de 400 metros da pista para realizar o evento pago chamado "Sexta-Quente".
A distinção entre os "rachas" de rua, os clandestinos, e os do autódromo, os institucionalizados, e o debate daí decorrente, observados na pesquisa de campo, poderão contribuir para precisar a discussão de Elias e Dunning (1992) sobre o tema da busca de excitação nas sociedades modernas. A prática dos "rachas" parece nuançar as fronteiras entre os conceitos de excitação séria, produzida, segundo os autores, pelas situaçóes que se vive no cotidiano com riscos e perigos reais, e o de excitação jogo, ou a emoção produzida pela mimesis de situaçóes reais em espaços controlados. Embora façam essa distinção, os próprios autores ressaltam que, apesar da excitação mimética — produzida nos jogos, esportes, atividades de lazer e também filmes, teatro, concertos, danças e pinturas ser desprovida de perigo real, e a excitação séria permitir a perda do autocontrole, podendo tornar-se uma ameaça, os limites entre o controle e o descontrole podem sempre ser ultrapassados, a exemplo da violência no futebol ou nos festivais de música $p o p$.

Neste sentido, trabalho com a hipótese de que nos "rachas" de rua os jovens buscam o risco ou o perigo "real", melhor dizendo, buscam os sentimentos mais próximos das emoções presentes na excitação séria, aquelas experimentadas em situaçôes da vida "real". Eles buscam vivenciar o risco lidando com os imponderáveis das situações "reais": confrontar-se com outros carros no trânsito; lidar com os defeitos das ruas, vias públicas e estradas; e, ainda, com a possibilidade de serem presos, já que se trata de uma prática ilegal. Já nos eventos organizados no autódromo da cidade, que contam com a anuência do poder público, haveria uma tentativa de institucionalizar a prática, controlando os riscos ou perigos "reais" com medidas de segurança que diminuem a margem do imponderável: regras para a "arrancada" de dois em dois carros a cada vez; distância definida a ser percorrida; conservação da pista, ausência 
de trânsito, presença dos bombeiros e de uma ambulância no local, dentre outros. O objetivo seria o de fazer os jovens abandonarem a excitação séria em troca da excitação jogo, mimética das emoçóes e dos sentimentos encontrados em situaçóes reais. Estaríamos diante da moderna expressão do sentido do risco: o risco sob o controle da tecnologia, e não é à toa que se desenvolvem na modernidade diversas tecnologias de segurança e proliferam seguros para os mais diferentes tipos de risco.

\section{Estilos de masculinidade: o carro como extensáo de seu próprio corpo}

A predominância de homens jovens nos "rachas" de carros e de motos, corridas, acidentes de trânsito e outras práticas relacionadas à velocidade leva Ribeiro (2003, p. 60) a afirmar, no estudo sobre motociclistas portugueses, que o fato de essa prática envolver a utilização de instrumentos complexos faz com que a "conjugação do risco físico e da sofisticação técnica produz[a], por meio da socialização, uma barreira sexual que torna improvável a presença de mulheres". Tal predominância do sexo masculino nas práticas relacionadas à velocidade é fruto dos processos de aprendizagem vividos pelos dois gêneros, o masculino e o feminino, desde a infância, nos quais se reforçam habilidades masculinas para atividades que envolvem força física e domínio técnico. A linguagem do mundo das motos e dos carros é expressa pelas ideias de potência, cilindragem, aceleração, rapidez, performance.

No material analisado, a questão do desempenho é recorrente na fala dos jovens. Há uma constante dúvida sobre a veracidade da velocidade alcançada mencionada pelos participantes $\mathrm{da}$ comunidade. Alguns questionam se as informações apresentadas quanto à potência do motor ("montado", "preparado"; "turbinado") são corretas, mas principalmente se a velocidade atingida é verdadeira. Apesar de existir uma diferença entre velocidade real atingida pelo carro (ou moto) e aquela marcada pelo velocímetro, os jovens parecem não acreditar no que diz a maioria, sobretudo quando a afirmação lhes parece exagerada. Alguns se irritam, dizendo que aquela deveria ser uma comunidade séria e não de "mentirosos", "pescadores" ou "contadores de vantagens". Parecem alegar que o exagero leva à descrença e à ridicularização, colocando em dúvida a legitimidade da comunidade.

A impressão que se tem é que eles próprios têm consciência da possibilidade de potencializarem seu prestígio e status - na construção de um estilo de masculinidade - frente a outros jovens, colegas, amigos ou membros da comunidade, desde que as características apresentadas não pareçam exageradas ou inverossímeis. Há uma negociação e controle das informaçóes repassadas na comunidade para que não se exagere demasiadamente e se possa garantir a sustentabilidade da comunicação. Vejam como se expressam nestes casos: "é uma ilha da fantasia [...] Peter Pan"; "carro com turbina de concorde da Air France"; "com motor de helicóptero"; "bicicleta com motor de geladeira"; "mentem tanto que daqui a pouco chegam a velocidade da luz".

Alguns deixam transparecer que nem todos os participantes realizaram de fato o que ali estão relatando. Parece que nos encontramos entre o real e o desejado. Há sempre exigências de fotos ou filmes para comprovação do que está sendo dito. É como se fosse um sonho não realizável, ou por impossibilidade financeira de ter um carro "turbinado", ou por outras razóes conforme afirmam os jovens: "estava com dois muleke no carro", "a estrada estava molhada”, "família dormindo dentro do carro". Neste sentido, há manifestaçôes que expressam um sentimento de "vergonha" e mesmo de inferioridade por não poderem ter um carro "fuçado", 
“canhão", "animal”, "nervoso". As referências são sobre as qualidades superiores e inferiores dos carros ou motos, simbolicamente atribuídas também ao seu proprietário ou condutor.

O tom de cinismo, presente na resposta de alguns incitados a contarem a verdade sobre a velocidade atingida, demonstra o quanto a coragem de desafiar o perigo é um valor importante nesta comunidade; necessidade de se sobressair, de identificar-se, de tornar-se herói aos olhos dos outros. São poucas as manifestações de garotas nestes tópicos de discussão aqui apresentados, entretanto, suas falas são significativas ao reforçarem este valor da coragem masculina. Uma delas pediu prova: "se vc é homem vem mostrar que atingiu esta velocidade"; a outra disse: "filme e coloque no site p/ gente ver se é verdade".

Pode-se refletir aqui sobre os limites da pesquisa virtual, pois, conforme já alertara Malinowski (1984), pode haver distância entre o que se afirma (normas) e o que se faz na prática (negociação das normas). A necessidade da observação da prática - observação participante - é ressaltada, aliás, mesmo para as pesquisas de campo, pois uma pesquisa que prioriza os dados coletados por técnicas de entrevistas, dando ênfase a uma análise das representaçóes, pode trazer um viés próprio da distância que pode existir entre "o que é dito" e "o que é feito". Isso justifica a associação dos dados coletados na Internet com a observaçáo de campo, pois permitirá a relativização dos testemunhos relatados nas comunidades, considerados exagerados ou até mesmo falsos por parte de alguns membros. Eles consideram que alguns relatos exageram na velocidade atingida, na potência dos motores e nas habilidades do motorista, o que pode ser compreendido como uma tentativa de reforçar valores próprios de um estilo de masculinidade. Nesse caso, o anonimato relativo propiciado pela Internet poderia estar contribuindo para isso. Além disso, como o objetivo da pesquisa é buscar compreender o sentido do risco para os jovens com relação à velocidade, a forma como o risco é vivido e enfrentado na prática é importante contraponto para a forma como ele é pensado e valorizado em termos de representação.

\section{Consideraçóes finais}

Apesar de ainda preliminar, a pesquisa permite trabalhar com o pressuposto de que os grupos que se relacionam na Internet em torno da experiência e do significado da velocidade, compartilham linguagens de pertencimento, significados, gostos e sensibilidades que possibilitam a construção de processos identitários, mesmo que provisórios e instáveis.

A conduta de correr risco, sob a pressão de ser apanhado pela polícia e de poder morrer em um instante (o imponderável, o descuido), impóe a sensação do "instinto do instante" e a do reconhecimento, de acordo com Pais (2004), tão valorizadas na sociedade contemporânea, permitindo a expressão da individualidade e a possibilidade de ganhar um nome próprio entre os usuários e amigos.

A busca do prazer nas sensaçóes corpóreas produzidas pelo som intenso e pelas vibrações dos motores, mudando os registros de percepção do tempo (realidade suspensa), do peso e da gravidade do corpo, pode representar uma forma de intensificar os sentidos (associado à adrenalina), amortecidos pela modernidade que habituou os corpos à rapidez e à aceleração. As sensações, descritas pelos jovens na experiência relatada da velocidade, indicam uma referência à busca da vertigem que leva à renúncia da consciência e da vontade, deixando-os à deriva, embriagados por forças estranhas, como forma de reação ao mundo moderno, dominado pela tendência à individualização e às formas de controle social e de autodomínio. Entretanto, 
arrisco dizer, forma de vertigem sob controle porque pressupóe segurança técnica do carro "preparado" e do motorista que deve dominar o automóvel em velocidade com atenção redobrada, concentração e responsabilidade. Autodomínio entremeado de sensaçóes de "sair do tempo", ou melhor, vertigem controlada sob o signo da modernidade e da tecnologia.

\section{Field research in illegal street races online communities: speed, risk and masculinity}

abstract This article is part of a research project with the purpose of understanding the risk conduct present in illegal street racing, and the meanings they have for the young people who practice it. Speed has acquired an important value in modern western societies, in which several forms of risk proliferate, creating, at the same time, doubt and the search for safety. Unlike the way that risks are controlled in a technologized and securitarian world, some juvenile groups try to expose themselves to them, widening and challenging them, sometimes, until the limit of life and death. Speed is shown as one of the main features of the urban revolution and modern life, and the car is one of possible synthesis of the changes that occurred. The purpose of this article is to present initial theoretical considerations about this theme, based on the analysis of discussion lists on the Internet, and methodological observations about the study of an illegal practice that instigates the ethnographical approach.

keywords Youth. Speed. Illegal Street Racing. Cars. Risk.

\section{Notas}

1 Parte dessas observaçóes metodológicas foi por mim publicada, de forma modificada, na revista Altérités (Jeolás, 2008).

2 O Orkut (www.orkut.com) é um site de relacionamento com mais de 21 milhóes de usuários, surgido há pouco mais de quatro anos, que permite exibir e trocar perfis pessoais, fotos, recados, e-mails e listas de discussão nesses fóruns ou comunidades disponíveis na rede Internet. Desses milhôes de usuários, 70\% são brasileiros (www.insideorkut.blogspot.com).

3 Ser associada aos profissionais da imprensa em busca de reportagens, muitas vezes sensacionalistas, é comum nos vários locais em que a pesquisa de campo vem sendo realizada, inclusive nos encontros quinzenais no autódromo, quando o "racha" é institucionalizado, não constituindo, portanto, uma prática ilegal. É que os jovens transitam nesses vários locais e têm receio de poderem ser identificados pela polícia. Temos que estar sempre desfazendo a primeira impressão de sermos jornalistas, principalmente quando usamos a câmera de filmar e papel para anotaçóes.

$4 \mathrm{Na}$ pesquisa de campo, minha interação está sendo mediada por um aluno, participante do universo dos "rachas" há muitos anos na cidade, o que tem facilitado o trabalho, fazendo com que, em muitas ocasiōes, a condição de professora atribua um status de legitimidade à pesquisa e ao vídeo que está sendo realizado sobre eles.

Por exemplo, cito as disputas existentes, e observadas pelos meus informantes, entre os dodgeros (Dodge da Chrysler) que se opóem aos opaleros (Opala da Chevrolet) que, por sua vez, se opóem aos cheveteros (Chevette da Chevrolet).

6 As expressões tunado ou tunar vêm do termo em inglês tuning e significam sintonia entre todas as partes do carro para obtenção de maior potência e velocidade. Atualmente, as modificaçóes podem se dar tanto no motor, para aumentar sua potência, como nos acessórios, acrescentados para melhorar a aerodinâmica e promover o desempenho, ou mesmo, simplesmente, por questão de estética e de estilo.

Apesar das listas de discussão dessas comunidades estarem disponíveis à consulta para quem tiver interesse e todas elas terem aceito meu pedido de participação, optei por resguardar o anonimato, não citando nem o nome nem o endereço das mesmas.

8 Almeida (1996, p.20) defende o termo incorporação para a tradução do inglês embodiment, cujo significado, para o autor, refere-se ao aprendizado e à assimilação realizados através do corpo e apenas nele observáveis.

9 Entretanto, essa relação masculinidade/risco só pode ser analisada com referências etnográficas e não deve ser generalizada de maneira direta e mecânica. Como 
exemplo desse exercício, Sánchez (2005) propóe relativizar e aprofundar os estudos que correlacionam de forma genérica as formas hegemônicas de socialização do homem, voltadas para atitudes e comportamentos de coragem, de agressividade, de combate, de competitividade e de desafio aos perigos, com condutas opressivas, violentas e de risco. Segundo o autor, esses estudos podem criar estereótipos essencialistas de "machos" propensos à violência e ao perigo, estabelecendo um vínculo direto, mecânico e sem questionamento entre masculinidade e condutas de risco. Em seu estudo sobre uma comunidade rural mexicana, ele mostra como o modelo dominante de masculinidade não condicionou significativamente $\mathrm{a}$ ocorrência das mortes por acidentes e outras causas violentas. Localmente, a responsabilidade, a disciplina e o respeito em relaçáo às mulheres, aos velhos e às crianças são características exigidas de um "homem de verdade", o que leva esses homens a evitarem uma série de práticas de risco que poderiam pôr em perigo a sua vida e a de outras pessoas.

10 Termo em inglês que se refere à manobra de queimar pneus com o carro parado até estourarem. Em português a prática é também conhecida como "borrachão". Pude perceber aí os elementos de destruição, agonismo e prestígio, como no potlach analisado por Mauss (1974), mas potlatch em uma sociedade de classe e de mercado, na qual os jovens só podem fazer o burnout com pneus usados e velhos que seriam descartados, a não ser que tivessem poder aquisitivo para comprar pneus novos.

\section{Referências bibliográficas}

ABRAMO, W. Helena. Cenas juvenis: punks e darks no espetáculo urbano. São Paulo: ANPOCS, 1994.

ALMEIDA, Miguel Valle de. Senhores de si. Uma interpretação antropológica da masculinidade. Lisboa: Fim de Século, 2000.

(Org.). Corpo presente. Treze reflexões antropológicas sobre o corpo. Oeiras: Celta Ed., 1996.

AUGÉ, Marc. Não-lugares: introduçẫo a uma antropologia da supermodernidade. Campinas, SP: Papirus, 1994.

BALANDIER, Georges. Le désordre: éloge du mouvement. Paris: Fayard, 1988.

. Le Dédale: pour en finir avec le XXe siècle. Paris: Fayard, 1994.
BECK, Ulrich. "Momento cosmopolita" e sociedade de risco. Com Ciência - SBPC - Revista Eletrônica de Jornalismo Científico. Dossiê Risco, n.104, 10/12/2008. Disponível em: <http://www.comciencia.br/comciencia/handler.php?section $=8 \&$ edicao $=41$ \&id=501 >. Acesso em 12/dez/2008.

BOURDIEU, Pierre. Esboço de uma teoria da prática. In: ORTIZ, Renato. (Org.). Pierre Bourdieu. São Paulo: Ática, 1994.

A dominação masculina. Educação \& Realidade, v. 20, n.2, p. 133-184, jul./dez., 1995.

Razóes práticas. Sobre a teoria da ação. Campinas, SP: Papirus, 1996.

CAILLOIS, Roger. Los juegos y los hombres: la máscara y el vértigo. México: Fondo de Cultura Econômica, 1986.

CARMO, Paulo Sérgio. Culturas da rebeldia. A juventude em questão. São Paulo: Ed. SENAC, 2001.

CECCHETTO, Fátima Regina. Violência e estilos de masculinidade. Rio de Janeiro: Editora FGV, 2004.

CONNELL, R. W. La organización social de la masculinidad. In: VALDÉS, Teresa.; OLAVARIA, José. (Eds.). Masculinidadles. Poder y crisis. Santiago de Chile: Ed. de las Mujeres n. 24; Isis Internacional, 1997. p. 31-48.

CSORDAS, Thomas. J. A corporeidade como um paradigma para a antropologia. In: Corpolsignificado/cura. Porto Alegre: Ed da UFRGS, 2008.

DI GIULIO, Gabriela. M.; FIGUEIREDO, Bernardino R. de; FERREIRA, Lucia da C. Comunicação e governança do risco: um debate necessário. Com Ciência - SBPC - Revista Eletrônica de Jornalismo Científico. Dossiê Risco, n.104, 10/12/2008. Disponível em:

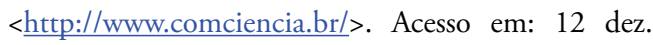
2008.

DORNELLES, Jonatas. Antropologia e Internet: quando o "campo" é a cidade e o computador é a "rede". Horizontes Antropológicos, v.10, n.21, p.241-271, 2004.

DOUGLAS, Mary. Pureza e perigo. São Paulo: Perspectiva, 1976.

Risk and blame: essays in cultural theory. Londres: Routledge, 1994.

La aceptabilidad del riesgo según las ciencias sociales. Barcelona: Paidós, 1996.

ELIAS, N. O processo civilizador. Uma história dos costumes, vol. 1. Rio de Janeiro: Jorge Zahar Ed., 1994.

Tecnização e civilização. In: NEIBURG, F.;

WAIZBORT, L. (Orgs.). Escritos e ensaios, vol.1. Rio de Janeiro: Jorge Zahar Ed., 2006.

ELIAS, Norbert; DUNNING, Eric. A busca da excitação. Lisboa: Difel, 1992. 
FEARTHERSTONE, Mike (Ed.). Theory, Culture \& Society. Special Issue on: Automobilities, Sage Publications, v.21, n.4/5, August-October 2004.

FEATHERSTONE, Mike; HEPWORTH, Mike; TURNER, Bryan S. The Body. Social process and cultural theory. London, Thousand Oaks, New Delhi: Sage Publications, 1992.

FEIXA, Carles. El reloj de arena. Culturas juveniles en México. México: Centro de Investigación y Estudios sobre Juventud, 1998.

FOUCAULT, Michel. Microfisica do poder. Rio de Janeiro: Graal, 1979.

. História da sexualidade. A vontade de saber. Vol. 1. Rio de Janeiro: Graal, 1985.

GIDDENS, Anthony.; BECK, Ulrich.; LASH, Scott. Modernização reflexiva. Política, tradição e estética na ordem social moderna. São Paulo: Ed. UNESP, 1997.

GUIMARÃES JR., Mário J. L. O ciberespaço como cenário para as ciências sociais. Ilha - Revista de Antropologia 2(1), Universidade Federal de Santa Catarina (UFSC), 2000.

HANNERZ, U. Being there... and there... and there! Reflections on multi-site ethnography. Ethnography, v. 4, n.2, 2003.

HARAWAY, D. J. Manifesto ciborgue: ciência, tecnologia e feminismo-socialista no final do século XX. In: SILVA, T. T. (Org.). Antropologia do ciborgue: as vertigens do pós-humano. Belo Horizonte: Autêntica, 2000.

HOUAISS. Dicionário Eletrônico da Língua Portuguesa. Instituto Antonio Houaiss; Editora Objetiva Ltda. Versão 1.0, dez 2001.

JEOLÁS, Leila Sollberger. Les courses illégales de voitures: le cyberespace comme terrain ethnographique. Altérités - Revue québecoise des étudiants en anthropologie, vol 5, p.54 - 64, 2008. Disponível em: <http://www.alterites.ca>. Acesso em: 28 ago. 2008.

KANASHIRO, Marta. Controle do risco: uma tarefa infindável. Com Ciência - SBPC - Revista Eletrônica de Jornalismo Científico. Dossiê Risco, n.104, 10/12/2008. Disponível em: http://www.comciencia. brl. Acesso em 12/12/2008.

KIMMEL, Michael. S. A produção simultânea de masculinidades hegemônicas e subalternas. Horizontes Antropológicos. Dossiê: Corpo, Doença e Saúde, n. 9, 1998.

KUNDERA, Milan. A lentidão. Rio de Janeiro: Nova Fronteira, 1995.

LACROIX, Michel. O culto da emoçấo. Rio de Janeiro: José Olympio, 2006.
LATANZA, Marcella. A mulher à procura de um novo corpo: beleza, cirurgia estética e risco no ciberespaço, 2007. Trabalho de Conclusão de Curso (Ciências Sociais) - Universidade Estadual de Londrina. Londrina, 2007.

LE BRETON, David. Anthropologie du corps et modernité. Paris: PUF, 1990.

. Passions du risque. Paris: Métailié, 1991. Adeus ao corpo. Campinas, SP: Papirus, 2003. Conduites à risque. Des jeux de mort au jeu de vivre. Paris : PUF, 2004. A sociologia do corpo. Petrópolis, Rio de Janeiro: Vozes, 2006a.

. La saveur du monde. Une anthropologie des sens. Paris: Métailié, 2006b.

LÉVY, Pierre. O que é virtual?. São Paulo: Editora 34, 1996.

MACHADO, Lia Zanotta. Masculinidades e violências: gênero e mal estar na sociedade contemporânea. In: SCHPUN, M. R. Masculinidades. Sáo Paulo: Boitempo, 2004.

MADEIRA, Felícia. R. Os jovens e as mudanças estruturais na década de 70: questionando pressupostos e sugerindo pistas. Cadernos de Pesquisa. SP, n. 58, p. 15-48, ago. 1986.

MAGNANI, José Guilherme Cantor. De perto e de longe: notas para uma etnografia urbana. Revista Brasileira de Ciências Sociais - RBCS, v. 17, n. 49, p. 11-29, 2002.

MALINOWSKI, B. Objetivo, método e alcance desta pesquisa; Introdução: o assunto, o método. In: Malinowski. São Paulo: Ática, 1984.

MARCUS, G. Identidades passadas, presentes e emergentes: requisitos para etnografias sobre a modernidade no final do século XX ao nível mundial. Revista de Antropologia. SP, n.34, p. 197-221, 1991.

Ethnography in/of the world system: the emergence of multi-sited ethnography. Annual Review of Anthropology, v. 24, p. 95-117, 1995.

MAUSS, Marcel. Sociologia e antropologia, v.2. São Paulo: E.P.U., 1974.

MILLER, Daniel; SLATER, Don. Etnografia on e offline: cibercafés em Trinidad. Horizontes Antropológicos, Porto Alegre, ano 10, n. 21, p. 41-65, 2004.

MORIN, Edgar. Cultura de massas no século XX: o espírito do tempo. Necrose, vol 2. Rio de Janeiro: Forense Universitária, 1986.

ORTNER, Sherry. B. Uma atualização da teoria da prática. In: GROSSI, Miriam P.; ECKERT, Cornelia.; FRY, Peter. H. (Orgs.). Conferências e diálogos: saberes 
e práticas antropológicas. Blumenau, SC: Nova Letra, 2007 (25a. Reunião Brasileira de Antropologia - Goiânia 2006)

PAIS, José Machado; CABRAL, Manuel Villaverde (Coords.). Condutas de risco, práticas culturais e atitudes perante o corpo. Resultados de um inquérito aos jovens portugueses. Oeiras, Portugal: Celta, 2003.

PAIS, José Machado. Introdução. In: PAIS, José Machado; BLASS, Leila Maria da Silva (Orgs.). Tribos urbanas. Produção artística e identidades. São Paulo: Annablume, 2004, p. 9-21.

PARENTE, A. (Org.). Imagem Máquina: a era das tecnologias do virtual. Rio de Janeiro: Ed 34, 1993.

PEIRANO, Mariza. A favor da etnografia. Rio de Janeiro: Relume-Dumará, 1995.

PERETTI-WATEL, P. Sociologie du risque. Paris: Armand Colin, 2003.

POCIELLO, Christian. Os desafios da leveza: as práticas corporais em mutação. In: SANT'ANNA, Denise Bernuzzi de (Org.). Politicas do corpo: elementos para uma história das práticas corporais. São Paulo: Estação Liberdade, 1995. p. 115-120.

RAMOS, Alcida. R. Ethnology brazilian style. Universidade de Brasília: trabalhos em Ciências Sociais, Série Antropologia, 89, p.1-38, 1990.

RIBEIRO, Fernando Bessa. Os modernos cavaleiros do asfalto: risco e transgressão nas estradas portuguesas. Cadernos do Nororeste. Sociedade e Cultura, 5, Universidade do Minho, Braga, Portugal, v. 21, n.4/5, p. 53-68, 2003.

RIFIOTIS, Theophilos. Antropologia do ciberespaço. Questôes teórico-metodológicas sobre pesquisa de campo e modelos de sociabilidade. Antropologia em Primeira Mão, n.51, Programa de Pós-Graduação em
Antropologia Social, UFSC, 2002.

RODRIGO, Enio. O ambiente das inovaçôes tecnológicas e o risco. Com Ciência - SBPC - Revista Eletrônica de Jornalismo Científico. Dossiê Risco, n.104, 10/12/2008. Disponível em: http://www.comciencia. brl. Acesso em: 12 dez. 2008.

SÁNCHEZ, Héctor. Eloy. R. El varón como factor de riesgo? Masculinidad y mortalidad por accidentes y otras causas violentas em la sierrra de Sonora. Estúdios Sociales. Revista de Investigación Científica, México, vol. XIII, n. 26, p.27-65, jul.-dic., 2005.

SENNET, Richard. Carne e pedra. O corpo e a cidade na civilizaçáo ocidental. Rio de Janeiro: Record, 1997.

SILVA, Daniela Ferreira Araújo. Do outro lado do espelho: anorexia e bulimia para além da imagem - uma etnografia virtual. Dissertação de Mestrado apresentada ao Departamento de Antropologia do IFCH da UNICAMP, 2004.

SPINK, Mary Jane. Construção social do risco na sociedade contemporânea. In: OLIVEIRA, Marlene; JEOLÁS, Leila S. (Orgs.). Anais do Seminário Cultura, Saúde, Doença. Brasília/Londrina: Programa das Naçôes Unidas para o Desenvolvimento (PNUD), 2003, p.127-140.

VELHO, Gilberto. Individualismo e cultura. Notas para uma antropologia da sociedade contemporânea. Rio de Janeiro: Jorge Zahar Eds., 1981.

VIRILIO, Paul. Velocidade e política. São Paulo: Estação Liberdade, 1996. . A bomba informática. São Paulo: Estação Liberdade, 1999.

\title{
autora Leila Sollberger Jeolás
}

Professora adjunta do Departamento de Ciências Sociais/UEL

Doutora em Ciências Sociais

\author{
Recebido em 26/03/2009 \\ Aceito para publicação em 06/11/2009
}

